\title{
Utilization of a telephone interactive voice-response tobacco cessation support service in the Islamic Republic of Iran
}

G. Heydari, ${ }^{1}$ A. Ebn Ahmady, ${ }^{2}$ H.A. Lando ${ }^{3}$ and B. Almasinia ${ }^{7}$

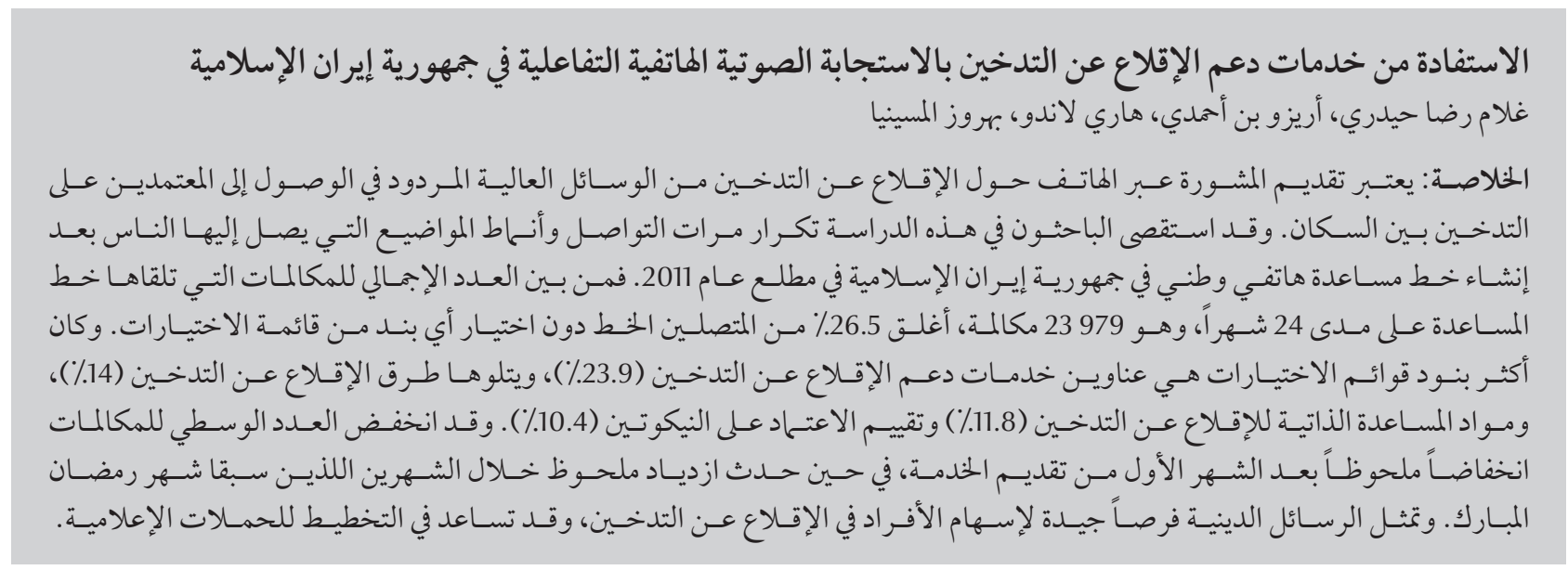

ABSTRACT Telephone smoking cessation counselling is a very cost-effective means of reaching dependent smokers in a population. We investigated the frequency of contacts and the types of topics that people accessed after a national telephone helpline was set up in the Islamic Republic of Iran at the beginning of 2011. From a total of 23979 calls received over a 24-month period, $26.5 \%$ of callers hung up without selecting any menus. The most frequently accessed menu was addresses of smoking cessation support services (23.9\%), followed by methods of smoking cessation (14.0\%), self-help materials for quitting smoking (11.8\%) and nicotine dependence assessment (10.4\%). The average number of contacts decreased dramatically after the first month of the service but there was a significant increase in the 2 months preceding the feast of Ramadan. Religious messages provide a good opportunity to engage individuals in smoking cessation and may be useful in the planning of media campaigns.

\section{Utilisation d'un serveur vocal interactif téléphonique d'aide au sevrage tabagique en République islamique} d'Iran

RÉSUMÉ L'aide au sevrage tabagique par téléphone est un moyen d'un très bon rapport coût-efficacité de toucher les fumeurs dépendants dans une population. Nous avons étudié la fréquence des appels et les différents types de sujets que les appelants sélectionnaient depuis la mise en place début 2011 d'une ligne téléphonique nationale d'aide aux fumeurs en République islamique d'Iran. Sur un total de 23979 appels reçus sur une période de 24 mois, 26,5\% des appelants raccrochaient sans sélectionner de choix dans les menus. Le menu le plus fréquemment sélectionné concernait les adresses des services d'aide au sevrage tabagique (23,9\%), suivi par les méthodes de sevrage tabagique (14,0 \%), puis par les outils d'auto-assistance pour le sevrage tabagique (11,8\%) et enfin par l'évaluation de la dépendance à la nicotine (10,4 \%). Le nombre moyen d'appels a diminué radicalement après le premier mois de mise en service mais a augmenté de manière importante dans les deux mois précédents la fête du Ramadan. Les messages religieux fournissent une bonne occasion pour encourager les consommateurs à renoncer au tabac et peuvent être utiles pour la planification des campagnes dans les médias.

'Tobacco Prevention and Control Research Center, National Research Institute of Tuberculosis and Lung Diseases, Shahid Beheshti University of Medical Sciences, Tehran, Islamic Republic of Iran. ${ }^{2}$ Department of Community Oral Health, School of Dentistry, Shahid Beheshti University of Medical Sciences, Tehran, Islamic Republic of Iran (Correspondence to A.Ebn Ahmady: aebnahmady@yahoo.com; a.ebnahmady@sbmu.ac.ir). ${ }^{3}$ Division of Epidemiology and Community Health, School of Public Health, University of Minnesota, Minneapolis, Minnesota, United States of America.

Received: 31/03/13; accepted: 10/12/13 


\section{Introduction}

The prevalence of smoking in the Islamic Republic of Iran was reported in the 2012 Tobacco atlas to be about $12 \%$ in the general population ( $25 \%$ in males and $2 \%$ in females) and ranked in the middle compared with other countries in the Eastern Mediterranean Region [1]. In the absence of appropriate measures in the field of tobacco control, the number of consumers of tobacco globally is predicted to continue to increase. Quitting smoking is a challenge for the majority of smokers [2,3], yet, with support from cessation counselling, smokers can increase the likelihood of overcoming their dependence [4]. Treatment of tobacco dependence includes a variety of techniques such as medical consultations, prescription of medications and telephone counselling. The cost of these techniques varies and they do not affect all smokers equally [5]. Cessation counselling at each medical visit reinforces the need to quit smoking [6,7], and consultations by health interns can also increase smokers' quit rates $[8,9]$.

Making smoking cessation counselling available to the total population of a country by telephone is a very useful and cost-effective means of reaching dependent smokers. These services are cheap, accessible and confidential and can accommodate smokers who are not able to call during office hours. Moreover, these services are available to residents of remote areas and can provide information to specific groups of people $[10,11]$. Traditional smoking cessation counselling by phone has shown significant results, although this only responds to calls initiated by smokers. Some cessation counselling helplines provide complementary services via the Internet and also allow continued use of the service as well as information about other related services $[12,13]$.

In the Islamic Republic of Iran, smoking cessation services began in 1998 with the launch of the first smoking cessation clinic by the Tobacco Prevention and Control Research Center $[14,15]$. Due to limitations of time and distance, attending these courses of treatment was impossible for many clients, and in 2005 this Centre established the first smoking cessation counselling telephone helpline with the use of physician operators [16]. However, making the service available at all times of the day and on holidays was not possible, and many clients failed to make contact because of busy lines. Therefore, in 2011 the first interactive voice-response (IVR)-based helpline for smoking cessation counselling in the country was established at our Centre. By using this system, smart evaluation of callers can be made and the best guidance for smoking cessation can be delivered.

The primary objective of this study was to evaluate the utilization rate of the newly established IVR helpline in the Islamic Republic of Iran and the secondary objective was to determine the most important information that smokers need.

\section{Method}

This was a cross-sectional study carried out over 24 months from 2010 to 2012.

\section{System design}

A national IVR-based telephone helpline was established for the Tehran area in 2010 using the computer telephony software AA Client, version 4.2.7.7, with an application generator output by the Tazarv Afzar Company based in the Islamic Republic of Iran.

Based on domestic and foreign researchers' experiences, we created 8 main menus to cover the following topics: hazards of smoking; methods of smoking cessation; self-help materials for smoking cessation; waterpipe smoking; medical treatments for smoking cessation; address of centres which provide smoking cessation services; level of nicotine dependence; and effects of smoking cessation (Figure 1). A caller to the helpline hears an introductory message with descriptions of each topic and enters the relevant number on the keypad to be routed to the topic areas and various branches within topics. Verbal messages, prepared using relevant educational materials based on up-to-date scientific resources, were collected in submenus for 4 of the topics - hazards of smoking; self-help materials for smoking cessation; waterpipe smoking; and the address of cessation centres. Listeners can make use of these according to their interests, time and needs. For the other 3 topics - effects of smoking cessation, methods of smoking cessation and medical treatments of cessation - after hearing about some initial materials, the caller can access supplementary topics by selecting numbers in the same menu. For the topic on nicotine dependence level, the caller's level of tobacco dependency can be assessed smartly through his/her answers to an audio version of the Fagerström test for nicotine dependence [17]. The responses are assessed by smart software and results in individualized recommendation about appropriate cessation methods.

\section{Implementation and data collection}

The helpline was initially publicized nationally using 2 announcements in 2 popular newspapers in December 2010 and 4 announcements on the national Radio Health programme in early 2011. Following public promotion, the helpline started to receive calls from the beginning of 2011 . After 24 months of operation, the number of callers to the helpline, menus selected, hours of contact and the time taken for each call were recorded and analysed.

\section{Data analysis}

The data are presented in the form of frequency distributions, means and standard deviation (SD) and the $t$-test 


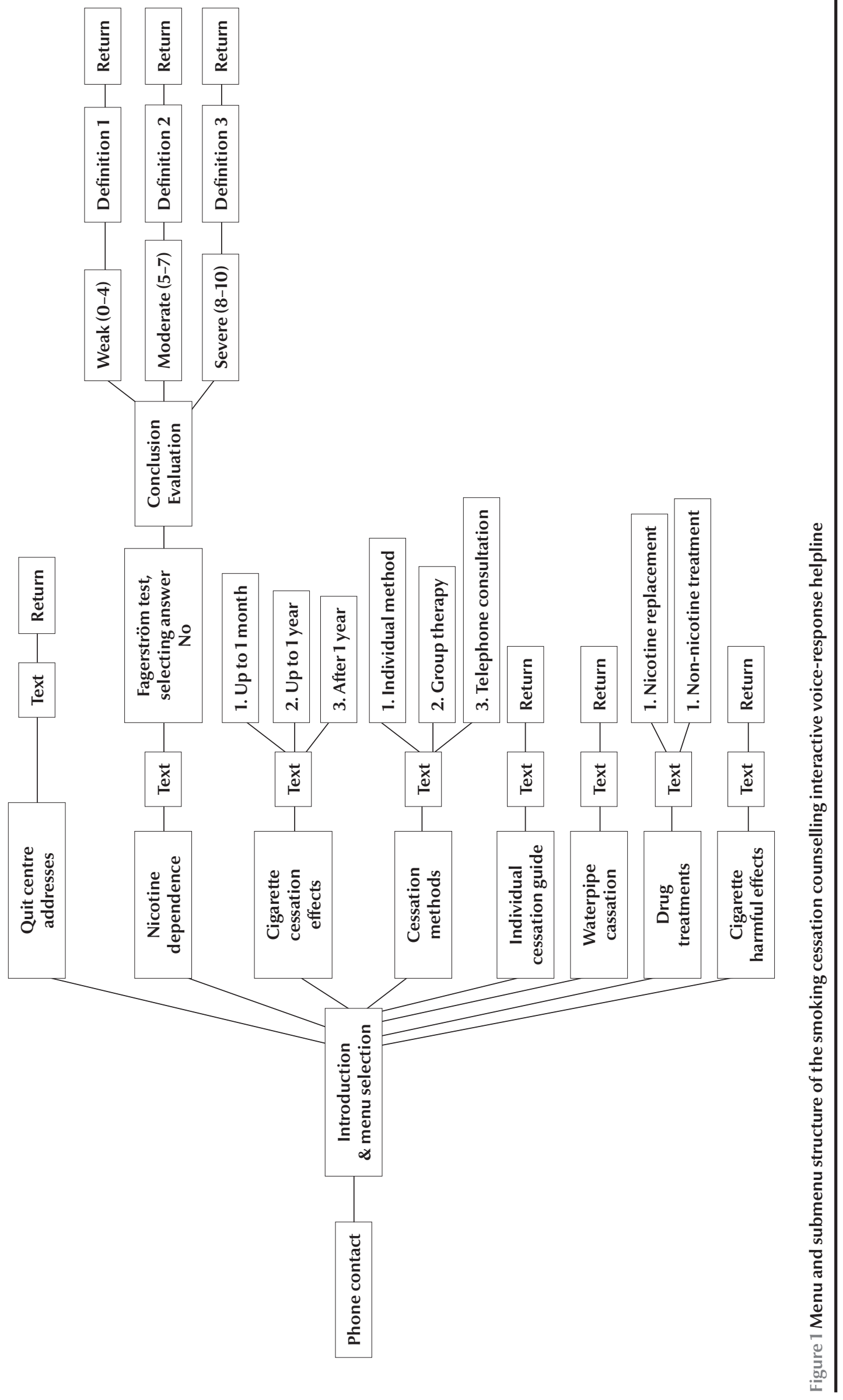




\begin{tabular}{lcc|}
\hline \multicolumn{3}{|c|}{ Table 1 Frequency distribution of interactive voice-response menus accessed by } \\
callers ( $\boldsymbol{n}=\mathbf{2 3}$ 979) to the tobacco cessation helpline in the first $\mathbf{2 4}$ months \\
\hline Menu topic & No. of calls & $\%$ \\
\hline Introduction only (caller hung up) & 6212 & 26.5 \\
Address of smoking cessation centres & 5741 & 23.9 \\
Methods of smoking cessation & 3270 & 14.0 \\
Self-help & 2757 & 11.8 \\
Nicotine dependence assessment & 2444 & 10.4 \\
Cigarette cessation effects & 1307 & 5.5 \\
Drug treatments for cessation & 859 & 3.2 \\
Smoking harm & 763 & 3.0 \\
Waterpipe smoking & 626 & 2.1 \\
\hline
\end{tabular}

was used to test for differences where appropriate. Descriptive statistics, percentages, frequencies and the $t$-test were used in this study. Statistical significance was set at $P$-value $<0.05$. Analyses were conducted using SPSS, version 17.0, and Microsoft Excel.

\section{Results}

During the first 24 months of monitoring the service, the number of calls to the helpline totalled 23979. From all calls, 6212 callers (26.5\%) hung up without selecting any menus or submenu branches. The remaining calls were routed to the next level of menus and then to submenu branches. The results indicated that the address of centres offering smoking cessation services was the most commonly accessed topic (used 5741 times, 23.9\%). The next most frequently accessed topics were methods of smoking cessation (14.0\%), self-help materials for quitting smoking (11.8\%) and the nicotine dependence assessment (Fagerström test) (10.4\%). The other 4 menus combined accounted for $14.9 \%$ of all contacts (Table 1).

In the first month of its operation, 7434 contacts were made to the helpline. After that, the number of calls decreased dramatically and the average number of calls to the helpline in the other 23 months of the survey was 614 (SD 720) per month. However, in
May and June 2011, the number of calls were 1455 and 1175 respectively and in May and June 20121942 and 2309 respectively, and these were significantly higher than during the other months after the first month $(t$-test, $P<0.05)$ (Figure 2).

Of the total calls, 8633 (36\%) were made from 08:00 to 16:00 hours, 12757 (53.2\%) from 16:00 to 24:00, and 2589 (10.8\%) from 24:00 to 08:00. The average time per call was 6.5 (SD 4.0) minutes.

\section{Discussion}

Our experience with the first smoking cessation counselling IVR phone line in the Islamic Republic of Iran indicated that, following the high initial public interest (presumably due to the initial media coverage), the Muslim feast of Ramadan was a key opportunity for providing support for smokers to quit.

When we analysed the number of calls and the topics which were accessed by callers, the highest percentage was to the address of centres which offer cessation services. This suggests a lack of sufficient publicity about these centres to the overall smoker population. An important point to note is that about $26.5 \%$ of calls ended at the main introduction menu of the system with no submenus accessed. This could be because the caller expected to talk to a person or a doctor and was not satisfied to hear a recorded message $[18,19]$.

The number of calls in the first year and especially in the first month of launch of the helpline was very high. Media advertisements for launching this service presumably generated considerable interest, but after that the average volume of calls reduced dramatically, probably due to the lack of sustained media coverage. A similar trend was seen in another study [20].

We demonstrated that the number of calls to the smoking cessation IVR helpline increased dramatically in the months before Ramadan (which coincided with mid-July of 2011 and 2012). This could be due to an increased tendency of Muslim smokers to attempt to quit smoking before Ramadan and to their need for support in refraining from smoking during daylight hours as part of their fasting duties during this month. Because this service can provide the basic information easily and with minimal cost, it is clearly justified. Similar results have not been reported previously, and to our knowledge no comparable studies have been performed. This could be due to lack of sufficient smoking cessation phone lines in many Islamic countries, or because in countries where this service is provided there are fewer Muslims, or even if the contacts are made they are not related to Ramadan.

Other researchers have reported that sudden increases in the number calls to smoking cessation phone lines can be linked to specific reasons. Harwel et al. in their study in the United States of America (USA) observed an increased number of calls to a smoking cessation phone line after the tax on cigarettes was raised and prices increased [21]. Willemsen et al. in The Netherlands noted an increase in telephone contacts related to adding new European Union visual warnings on cigarette packets [22]. Studies in the USA, by Bush et al. [23] and Deprey et al. [24], have also shown that other incentives in the form of free nicotine replacement patches 


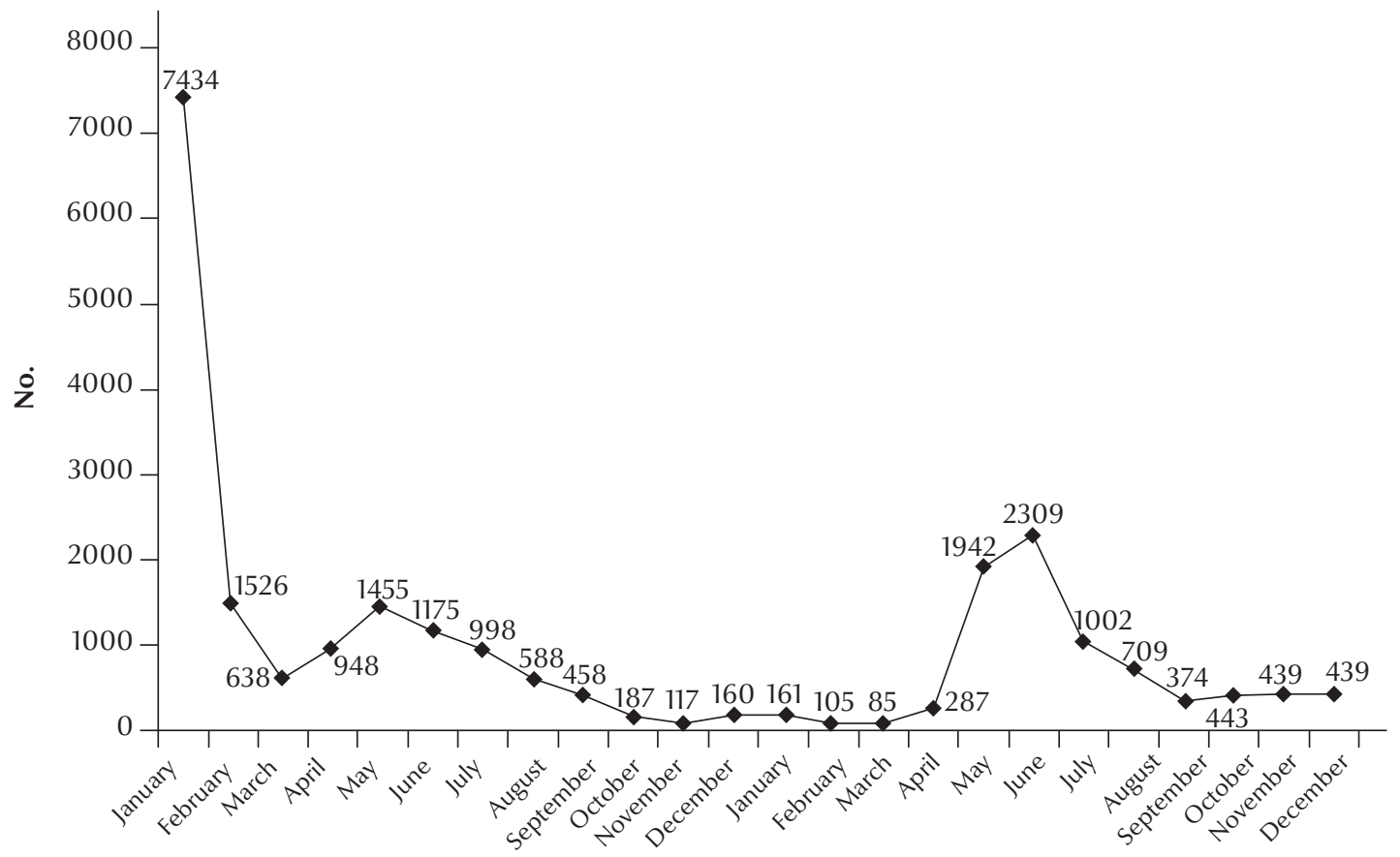

Figure 2 Monthly frequency of contacts with smoking cessation interactive voice-response helpline in Tehran during 24 months after the start of the service in 2011

were the reason for increased contact with smoking cessation phone lines. This could be considered as an important subject in other Islamic countries in which Ramadan fasting duties provide an incentive to quit or reduce the consumption of tobacco.

There were some imitations to the study. Because the telephone numbers of individuals in this study were kept confidential, the effectiveness of the service in terms of users' self-reported success at quitting and their comments about why and how they used the IVR were not investigated.

In conclusion, the results showed that the address of smoking cessation centres were the most requested service of the helpline and that more people seemed to wish smoking cessation counselling in the period just before Ramadan. Religious messages provide a good opportunity to engage individuals in smoking cessation and may be useful in the planning of media campaigns.

Competing interests: None declared.

\section{References}

1. Eriksen M, Mackav J, Ross H. The tobacco atlas, 4th ed. Atlanta, Georgia, American Cancer Society, 2012.

2. Doll R, Peto R, Boreham J, Sutherland I. Mortality in relation to smoking: 50 years' observations on male British doctors. BMJ, 2004, 328(7455):1519.

3. NHS Centre for Reviews and Dissemination. A rapid and systematic review of the clinical and cost effectiveness of bupropion SR and nicotine replacement therapy (NRT) for smoking cessation. York, University of York, 2002.

4. Lancaster T, Stead L. Physician advice for smoking cessation. Cochrane Database of Systematic Reviews, 2004, 4(4):CD000165.

5. Rice VH, Stead LF. Nursing interventions for smoking cessation. Cochrane Database of Systematic Reviews, 2004;1(1):CD001188.

6. Solberg LI, Maciosek MV, Edwards NM, Khanchandani HS, Goodman MJ. Repeated tobacco-use screening and intervention in clinical practice: health impact and cost effectiveness. American Journal of Preventive Medicine, 2006, 31(1):62-71.
7. Lancaster T, Stead LF. Individual behavioural counselling for smoking cessation. Cochrane Database of Systematic Reviews, 2005;2(2):CD001292.

8. Stead LF, Lancaster T. Group behaviour therapy programmes for smoking cessation. Cochrane Database of Systematic Reviews, 2005;2(2):CD001007.

9. Lichtenstein E et al. Telephone counseling for smoking cessation: rationales and meta-analytic review of evidence. Health Educ Res, 1996, 11(2):243-257.

10. Stead LF, Perera R, Lancaster T. Telephone counselling for smoking cessation. Cochrane Database of Systematic Reviews, 2006;3(3):CD002850

11. Borland R, Segan CJ, Livingston PM, Owen N. The effectiveness of callback counselling for smoking cessation: a randomized trial. Addiction, 2001, 96(6):881-889.

12. Macleod ZR et al. Telephone counselling as an adjunct to nicotine patches in smoking cessation: a randomised controlled trial. Medical Journal of Australia, 2003, 179(7):349-352. 
13. Masjedi MR et al. Effective factors on smoking cessation among the smokers in the first "smoking cessation clinic" in Iran. Tanaffos, 2002, 1(4):61-67.

14. Heydari GR et al. The effect of training and behavioral therapy recommendations on smoking cessation (a report of the first "smoking cessation clinic" in Iran). Tanaffos, 2003, 2(6):39-44.

15. Heydari G, Marashian M, Ebn Ahmady A, Masjedi M, Lando $\mathrm{HA}$. Which form of nicotine replacement therapy is more effective for quitting smoking? A study in Tehran, Islamic Republic of Iran. Eastern Mediterranean Health Journal, 2012, 18(10):1005-1010.

16. Heydari G et al. Efficacy of telephone quit-line for smokers in Iran: 12 months follow up results. Tannafos, 2011;10(3):42-48.

17. Heatherton TF et al. The Fagerström test for nicotine dependence: a revision of the Fagerström tolerance questionnaire. British Journal of Addiction, 1991, 86(9):1119-1127.

18. Asfar T et al. Trial design: The St. Jude Children's Research Hospital Cancer Survivors Tobacco Quit Line study. Contemporary Clinical Trials, 2010, 31(1):82-91.
19. Wadland WC et al. Practice-based referrals to a tobacco cessation quit line: assessing the impact of comparative feedback vs general reminders. Annals of Family Medicine, 2007, 5(2):135-142.

20. Bentz CJ et al. The feasibility of connecting physician offices to a state-level tobacco quit line. American Journal of Preventive Medicine, 2006, 30(1):31-37.

21. Harwell TS et al. Utilization of a tobacco quit line prior to and after a tobacco tax increase. Journal of Public Health Management \& Practice, 2007, 13(6):637-641.

22. Willemsen MC, Simons C, Zeeman G. Impact of the new EU health warnings on the Dutch quit line. Tobacco Control, 2002, 11(4):381-382

23. Bush TM et al. The impact of a free nicotine patch starter kit on quit rates in a state quit line. Nicotine \& Tobacco Research, 2008, 10(9):1511-1516.

24. Deprey $M$ et al. Using free patches to improve reach of the Oregon Quit Line. Journal of Public Health Management and Practice, 2009, 15(5):401-408. 